\title{
Indole-3-carbinol inhibits cell proliferation and induces apoptosis in Hep-2 laryngeal cancer cells
}

\author{
YA-QIU WANG, CHEN CHEN, ZHE CHEN, YONG XU, YAN WANG, \\ BO-KUI XIAO, SHI-MING CHEN and ZE-ZHANG TAO \\ Department of Otolaryngology, Head and Neck Surgery, \\ Renmin Hospital of Wuhan University, Wuhan 430060, P.R. China
}

Received December 13, 2012; Accepted January 29, 2013

DOI: $10.3892 /$ or.2013.2411

\begin{abstract}
Indole-3-carbinol (I3C) is an active component of cruciferous vegetables and markedly inhibits the growth of a variety of tumors. However, its role in laryngeal cancer remains obscure. The aim of the present study was to elucidate the possible mechanisms whereby I3C influences Hep-2 laryngeal cancer cell proliferation and apoptosis. Treatment with I3C dose-dependently and significantly inhibited Hep-2 cell proliferation, and at doses of 100 and $150 \mu \mathrm{M}, \mathrm{I} 3 \mathrm{C}$ induced cell morphological changes and promoted apoptosis. Following treatment of Hep-2 cells with I3C, we found that the protein expression of phosphatidylinositol-3-kinase (PI3K) p110 $\alpha$, PI3K p110 $\beta$, PI3K class III, p-PDK1, Akt, p-Akt and the downstream signaling proteins $\mathrm{p}-\mathrm{c}-\mathrm{Raf}$ and GSK3- $\beta$ were significantly downregulated. Additionally, tumor-bearing mouse models were constructed using BALB/c nude mice. The mice were subdivided into groups: pretreated with $\mathrm{I} 3 \mathrm{C}$, or treated with $\mathrm{I} 3 \mathrm{C}$ or an untreated control group. After 8 weeks, mice pretreated or treated with IC3 developed smaller tumors compared to the untreated control group, and the protein expression of PI3K p110 $\alpha$, PI3K class III, Akt, p-Akt and the downstream signaling proteins $\mathrm{p}-\mathrm{c}-\mathrm{Raf}$ and GSK3- $\beta$ in the tumors were significantly downregulated. Furthermore, no harmful side effect were observed in the heart, liver and kidney of the I3C-treated nude mice. In conclusion, I3C inhibited proliferation and induced the apoptosis of laryngeal tumor cells both in vivo and in vitro, and exhibited low toxicity to normal cells. The inhibitory effects noted with I3C treatment may depend on decreased phosphatidylinositol-3 kinase/serinethreonine kinase (PI3K/Akt) expression. This approach may be
\end{abstract}

Correspondence to: Dr Ze-Zhang Tao or Dr Shi-Ming Chen, Department of Otolaryngology, Head and Neck Surgery, Renmin Hospital of Wuhan University, Wuhan 430060, P.R. China

E-mail: taozezhang@hotmail.com

E-mail: shimingchen@163.com

Key words: laryngeal cancer, indole-3-carbinol, phosphatidylinositol-3 kinases, Akt, apoptosis applied to the clinical treatment of laryngeal tumors and in drug screening.

\section{Introduction}

Laryngeal cancer is one of the leading malignant tumors of the head and neck and is reported to have a higher incidence in highly developed countries (1). Male patients are at particular risk, with an annual rate of incidence of $\sim 3.5-5.5 / 100,000$ cases. By contrast, female patients are at a markedly lower risk with an annual rate of 0.6/100,000 cases. The mortality rate among men was $\sim 2.4 / 100,000$ cases and in women, the rate was $\sim 0.3 / 10$ million cases (1). There are various options for treatment of laryngeal cancer including the conventional approaches of surgery, chemotherapy and radiotherapy. However, the curative effect and rate remain poor and require significant improvement.

Although a number of chemotherapeutic drugs are available for the treatment of cancer, a highly effective and less toxic approach for treating laryngeal cancer is lacking. One potential resource for a new generation of therapeutics for the prevention and treatment of laryngeal cancer may be natural substances. For example, epidemiological studies suggest that the intake of broccoli, cauliflower and other cruciferous vegetables can significantly reduce the incidence of cancers of the bladder, pancreas, colon, lung and stomach (2-5). Indole3-carbinol (I3C) has recently been identified as an important tumoricidal component found in cruciferous vegetables and particularly in members of the genus Brassica (6,7). A number of studies have shown that I3C induces cell cycle arrest in the G1 phase in cancer cells $(8,9)$, promotes apoptosis $(8-10)$ and prevents tumor invasion and metastasis (11). It has been found that I3C promotes cell cycle arrest by downregulating cyclin-proteins such as cyclin D1 and cyclin E. Additionally, it is thought that IC3 induces apoptosis by mechanisms that depend on downregulation of the anti-apoptotic genes Bcl-2, Bcl-xL and survivin and by enhancing expression of Bax and by functionally activating caspase-3 and caspase-9 (9-12).

The phosphatidylinositol-3 kinase/serine-threonine kinase (PI3K/Akt) signaling pathway is involved in the activation of anti-apoptotic mechanisms, glucose metabolism and protein synthesis, all of which influence cell growth and proliferation $(13,14)$. Abnormal activation of the PI3K/Akt pathway is 
found in many malignancies. Moreover, it is becoming apparent that tyrosine kinase-mediated activation of PI3K may be important, for example, in the context of phosphorylated tyrosine kinase interacting with the p85 subunit or in the context of mutated Ras-binding to PI3K, which leads to the activation of PI3K.

In addition, somatic mutations may also play an important role. For example, mutation in the PTEN tumor-suppressor gene may disrupt the ability of PTEN to switch off the PI3K pathway. Recently a PIK3CA mutation was found to occur in $\sim 30 \%$ of epithelial tumors. Abnormal activation of PI3K and somatic mutations can collectively drive uncontrolled growth and cell proliferation during the development of tumors, including ovarian, breast, pancreatic, lung and colon cancer or indeed other malignancies $(13,15,16)$.

To the best of our knowledge there are few reports describing the application of I3C in the treatment of laryngeal cancer. Similarly, there currently exists no report concerning the mechanism of action of I3C and its putative relationship with PI3K/Akt. The present study aimed to determine the influence of $\mathrm{I} 3 \mathrm{C}$ on the proliferation and apoptosis of human laryngeal cancer using the Hep- 2 cell line and to determine the relevance of the PI3K/Akt signaling pathway. The main objective was to elucidate the potential tumoricidal mechanism of I3C and to provide a basis for tumor-targeting treatment and drug screening.

\section{Materials and methods}

Cell culture and preparation of I3C. The human laryngeal carcinoma Hep-2 cell line was obtained from the central laboratory at Wuhan University. Hep-2 cells were cultured in RPMI-1640 culture medium (Invitrogen Life Technologies Carlsbad, CA, USA) and supplemented with $10 \%$ heatinactivated fetal bovine serum (FBS; HyClone, Logan, UT, USA), $100 \mathrm{U} / \mathrm{ml}$ penicillin and $20 \mu \mathrm{g} / \mathrm{ml}$ streptomycin in a fully humidified incubator at $37^{\circ} \mathrm{C}$ and an atmosphere of $5 \% \mathrm{CO}_{2}$ in air. I3C (Sigma-Aldrich, St. Louis, MO, USA) was dissolved in dimethyl sulphoxide (DMSO) to a stock concentration of $1 \mathrm{M}$, and was subsequently diluted to concentrations of 50, 100 and $150 \mu \mathrm{M}$ for use in the experiments. The final concentration of DMSO in the $\mathrm{I} 3 \mathrm{C}$ preparations was $<0.5 \%$. In order to demonstrate that the final concentration of DMSO did not affect the laryngeal cancer cells, Hep-2 cells cultured in complete medium alone, without exposure to I3C (as the untreated control), and thus DMSO $(<0.5 \%)$, were used as the negative control group $(0 \mu \mathrm{M})$.

Assay of Hep-2 cell proliferation using CCK-8 reagent. Hep-2 cells were seeded into $96-$ well plates at a density of $1 \times 10^{3} / \mathrm{ml}$ in complete culture medium and stimulated with $\mathrm{I} 3 \mathrm{C}$ at $0,50,100$ or $150 \mu \mathrm{M}$ in replicates of 6 wells per concentration of I3C. An additional 6 wells contained culture medium alone as a blank control. After 0, 24, 48 and $72 \mathrm{~h}$, cells were treated with $10 \mu \mathrm{l}$ of CCK-8 reagent (Dongji, Japan) and incubated at $37^{\circ} \mathrm{C}$ for $1 \mathrm{~h}$. An automatic microtitre plate reader was set to zero according to the blank control wells. The absorbance (A) of the wells was read at a wavelength of $450 \mathrm{~nm}$. The percentage of cell proliferation inhibition was calculated according to the following formula: Cell proliferation inhibition $(\%)=$
(1 - average absorbance (A) of the experimental group/average absorbance (A) of the control group) $x 100 \%$.

Morphological assessment of Hep-2 cells. Hep-2 cells were seeded into 6-well plates in complete culture medium containing $0,50,100$ and $150 \mu \mathrm{M}$ of I3C. Separate wells were seeded with culture medium alone, as an untreated control group. The experimental group, negative control group $(0 \mu \mathrm{M}$ of I3C) and blank control group were seeded in triplicate. After $48 \mathrm{~h}$ of culture, the cells were stained with $2 \mu \mathrm{g} / \mathrm{ml}$ Hoechst 33258 (Beyotime, Shanghai, China) and observed under a fluorescence microscope equipped with a blue filter for the assessment of morphological changes. The nuclei of normal cells were uniformly blue, and by contrast, apoptotic cells showed densely stained pyknosis and nuclear fragmentation.

Assay of cell apoptosis by dual staining with Annexin $V$ and propidium iodide (PI). Hep-2 cells were seeded into 6-well plates and in complete culture medium containing $0,50,100$ and $150 \mu \mathrm{M}$ of $\mathrm{I} 3 \mathrm{C}$, and separate wells were seeded with culture medium alone as an untreated control group. Each group was seeded in triplicate. After $48 \mathrm{~h}$ of culture, the cells were harvested by centrifugation, resuspended in binding buffer, and successively incubated with $5 \mu$ l Annexin V-FITC and $5 \mu \mathrm{l}$ of PI (Multi Sciences, China) at room temperature for $15 \mathrm{~min}$. Apoptosis was determined by flow cytometric analysis using a FACSCanto ${ }^{\mathrm{TM}}$ II spectrophotometer (BD Biosciences, San Jose, CA, USA). For the flow cytometric dot plot, Annexin V staining was set as the horizontal axis and PI staining was set as the vertical axis. Mechanically damaged cells were located in the upper left quadrant, apoptotic or necrotic cells in the upper right quadrant, dual negative and normal cells in the lower left quadrant and early apoptotic cells in the lower right quadrant of the flow cytometric dot plot.

Western blot assay of PI3K, Akt, p-c-Raf and GSK3- $\beta$ expression. After $48 \mathrm{~h}$ of treatment with different concentrations of I3C, the cells were lysed in RIPA buffer to extract total cellular protein. Protein concentration was determined according to the BCA quantitative method, and $30 \mu \mathrm{g}$ of each protein sample was resolved by SDS-PAGE and the protein bands were transferred to a nitrocellulose membrane. Following protein transfer, the membrane was blocked for $1 \mathrm{~h}$ in the presence of 5\% skimmed milk proteins, following by incubation at $4^{\circ} \mathrm{C}$ overnight with the primary antibodies (Cell Signaling Technology, Inc., Beverly, MA, USA) targeted against PI3K p110 $\alpha$, PI3K p110 $\beta$, PI3K class III, p-PDK1, p-Akt, Akt, p-c-Raf, GSK3- $\beta$ and GAPDH (as an internal reference housekeeping protein). On the following day, the blots were incubated with a secondary antibody at room temperature for $1 \mathrm{~h}$, and specific protein bands were visualized by an enhanced chemiluminescence (ECL) assay kit (Pierce Biotechnology, Inc., Rockford, IL, USA).

Animal selection and breeding. Specific pathogen-free (SPF) female BALB/c nude mice (aged 4 weeks and weighing $\sim 18-20 \mathrm{~g}$ ) were obtained from Beijing HFK Bioscience Co., Ltd. (China). All animal husbandry practices and experimentation were carried out under SPF conditions. Prior to initiating the experiment, animals were provided with conventional feed 

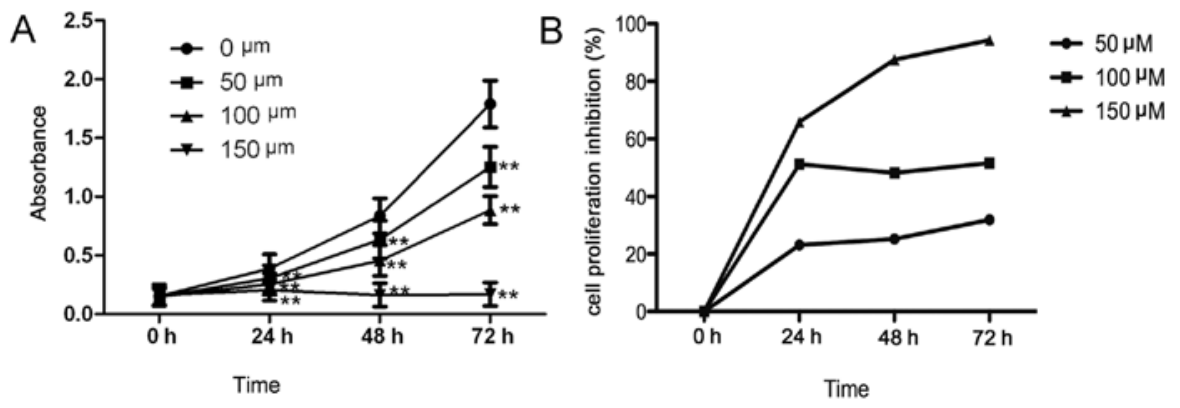

Figure 1. I3C influences Hep-2 cell proliferation. (A) Hep-2 cells were treated with I3C at concentrations of 0, 50, 100 and $150 \mu \mathrm{M}$, for 24,48 and $72 \mathrm{~h}$. The proliferation of the laryngeal carcinoma cells was detected by the CCK-8 method. The absorbance values of the wells are expressed as means \pm SD, ${ }^{* *} \mathrm{P}<0.01$ vs. negative control $(0 \mu \mathrm{M})$. (B) Relationship between the percentage of laryngeal cancer cell proliferation inhibition and different concentrations of I3C.

for 1 week (provided by Beijing HFK Bioscience Co., Ltd). Following this adaptive feeding, $\mathrm{I} 3 \mathrm{C}$ was incorporated into the conventional feed at a ratio of $0.5 \%(\mathrm{w} / \mathrm{w})$. All elements of this study were approved by the local Ethics and Animal Care and Use Committee of Wuhan University, China.

Establishing tumor-bearing animal models in $B A L B / c$ nude mice. Twenty-four female BALB/c mice were randomly assigned to a pretreatment group, a treatment group and a control group ( $\mathrm{n}=8 \mathrm{mice} / \mathrm{group})$. The Hep-2 cells were cultured to a confluence of $80-90 \%$, harvested by treatment with trypsin, and following centrifugation were resuspended in plasma. Hep-2 cells were adoptively transferred into mice at a density of $1 \times 10^{7}$ cells $/ \mathrm{ml}$, by injecting a $200-\mu$ l cell suspension in plasma subcutaneously into the right side of the back of nude mice. The pretreatment group was received the conventional feed supplemented with $\mathrm{I} 3 \mathrm{C}$ at a ratio of $0.5 \%(\mathrm{w} / \mathrm{w})$ for 2 weeks prior to adoptive Hep- 2 cell transfer and then received to a conventional feed following injection of the tumor cells. The treatment group received a normal conventional diet until one week after adoptive transfer with the Hep- 2 cells. At this time point, the tumors had grown to a size of $5 \times 5 \mathrm{~mm}$, and mice then received a feed supplemented with a $0.5 \%(\mathrm{w} / \mathrm{w})$ ratio of $\mathrm{I} 3 \mathrm{C}$. Mice were continued on the $\mathrm{I} 3 \mathrm{C}$ supplemented feed, until the experiment had reached the endpoint at week 8 . Mice in the control group were fed only conventional feed. At the end of each week following the adoptive transfer of the Hep-2 cells into the mice, the long diameter (a) and the short diameter (b) were measured in order to calculate the volume using the formula: $\mathrm{V}=1 / 2 \mathrm{ab}^{2}$ for statistical analysis. Eight weeks thereafter the mice were sacrificed, and specimens were collected from the tumor, heart, liver and kidney.

Protein extraction and expression assay. Tumor specimens from the sacrificed mice were cut into regularly sized pieces and minced using a tissue homogenizer. Immediately following this preparation, the cells were lysed in RIPA buffer, and the extracted proteins were quantified by the BCA method. Western blot assay was applied to detect the specific protein expression of PI3K, Akt, p-c-Raf and GSK3- $\beta$.

Morphological observation of the heart, liver and kidney tissue sections. Biopsy specimens of the heart, liver and kidney obtained from the nude mice were fixed in $10 \%$ formalin, dehydrated, embedded in wax, and sectioned into 5- to 8- $\mu \mathrm{m}$ specimens and pasted onto slides. Next, the specimens were de-waxed and stained with hematoxylin and eosin (H\&E) for final histological evaluation under a standard light microscope.

Statistical analysis. All statistical analyses were assessed by the SPSS statistical software package, version 16.0 for Microsoft Windows (SPSS Inc., Chicago, IL, USA). Results are expressed as means \pm standard deviation (SD). Differences between multiple groups were compared by ANOVA. $\mathrm{P}<0.05$ was considered to indicate a statistically significant result.

\section{Results}

Marked inhibition of laryngeal cancer cell growth following I3C treatment. Following the dose-dependent (50, 100 and $150 \mu \mathrm{M})$ and time-dependent $(24,48$ and $72 \mathrm{~h})$ treatment of Hep-2 cells with I3C, significant differences in cell growth were noted between the treated and negative control groups $(\mathrm{P}<0.01)$ (Fig. 1A). In the group treated with $50 \mu \mathrm{M} \mathrm{I3C}$ at the indicated time points of 24,48 and $72 \mathrm{~h}$, the percentage of Hep-2 cell proliferation inhibition was 23.12, 25.21 and $31.89 \%$, respectively. Additionally, in the group treated with $100 \mu \mathrm{m} \mathrm{I3C}$ the percentage of cell proliferation inhibition at 24,48 and $72 \mathrm{~h}$ was $51.17,48.22$ and $51.62 \%$ respectively. In the group treated with $150 \mu \mathrm{M} \mathrm{I3C}$, the percentage of cell proliferation inhibition at 24,48 and $72 \mathrm{~h}$ was $65.97,87.45$ and $94.26 \%$ respectively (Fig. 1B). Inhibition of the proliferation of Hep-2 laryngeal carcinoma cells by I3C was highly dosedependent.

Induction of laryngeal cancer Hep-2 cell apoptosis following I3C treatment. After Hep-2 cells were treated with I3C for $48 \mathrm{~h}$, the cells were stained with Hoechst 33258 and observed by fluorescence microscopy. In the negative ( $0 \mu \mathrm{M} \mathrm{I3C})$ and untreated control groups, Hep-2 cell nuclei displayed a normal and complete blue appearance. By contrast, in Hep-2 cells treated with 50,100 or $150 \mu \mathrm{M} \mathrm{I3C}$, the cells displayed enhanced fragmentation or pyknosis of the nuclei, which were typical changes associated with cellular apoptosis. Nuclear pyknosis and fragmentation in Hep-2 cells were significantly increased by treatment with $\mathrm{I} 3 \mathrm{C}$ in a dose-dependent manner. Morever, at an $\mathrm{I} 3 \mathrm{C}$ concentration of $150 \mu \mathrm{M}$, the ratio of pyknosis was $\sim 62 \pm 6 \%$ (Fig. 2).

The analysis of Hep-2 cell apoptosis by Annexin V-PI double staining showed that after $48 \mathrm{~h}$ of treatment with 0,50 , 


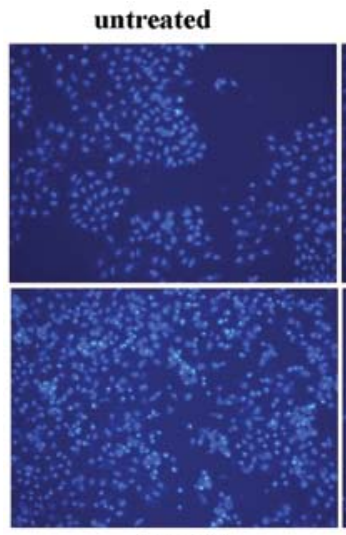

$100 \mu \mathrm{M}$

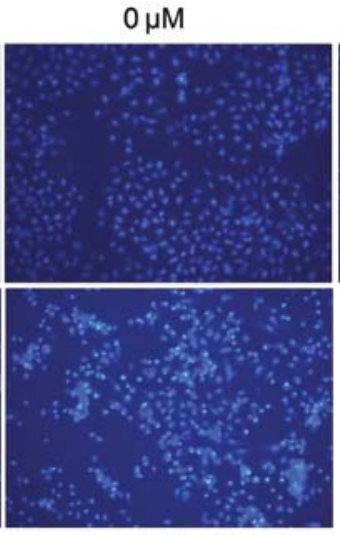

$150 \mu \mathrm{M}$

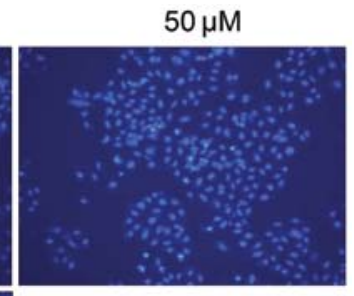

Figure 2. Morphological observation of Hep-2 cells treated with I3C and stained with Hoechst 33258 . Hep-2 cells were treated with I3C at concentrations of 0,50, 100 and $150 \mu \mathrm{M}$ for $48 \mathrm{~h}$, stained with $2 \mu \mathrm{g} / \mathrm{ml}$ Hoechst 33258 and observed under a fluorescence microscope (x200). Separate wells were seeded with culture medium alone as the untreated control group.
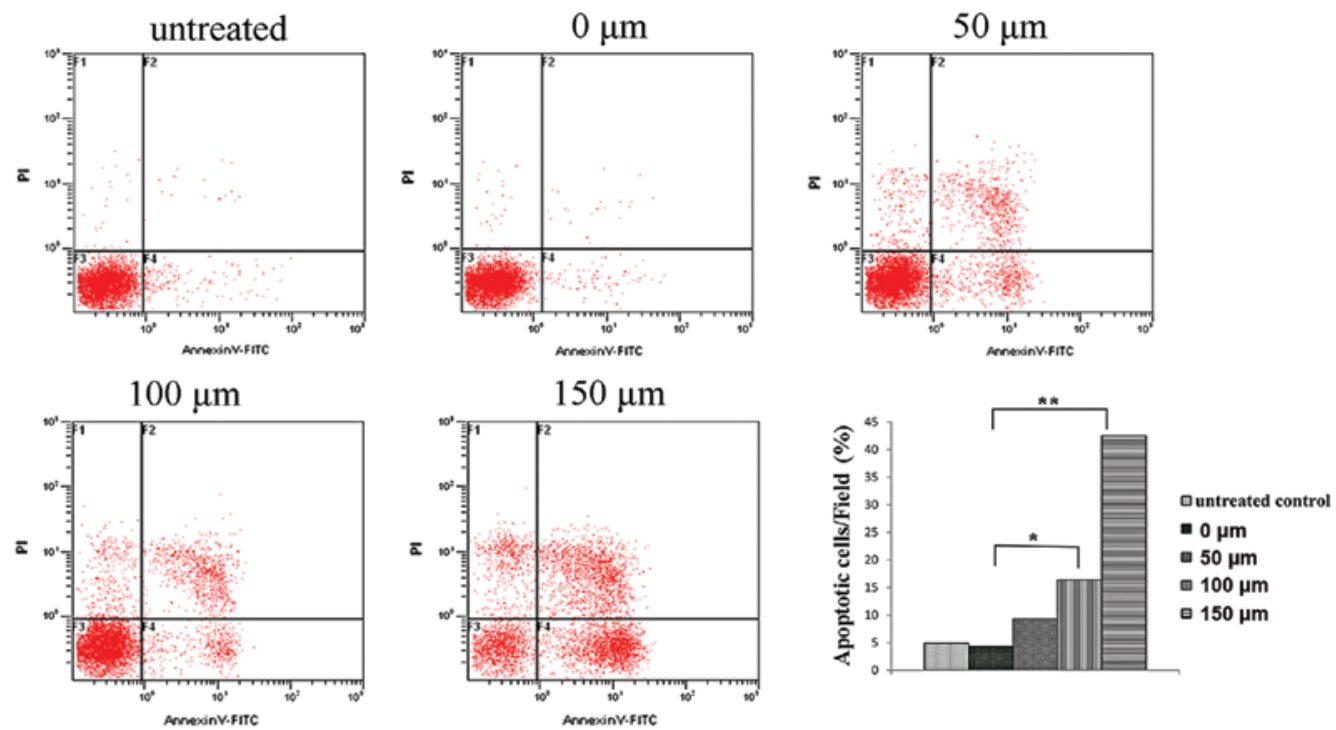

Figure 3. FACS analysis of the effect of I3C on laryngeal cancer cell apoptosis. Hep-2 cells were treated with $0,50,100,150 \mu \mathrm{M}$ of I3C or complete culture medium alone (untreated control) for $48 \mathrm{~h}$, and examined following Annexin V-PI double staining for the detection of the apoptotic rate. ${ }^{*} \mathrm{P}<0.05,{ }^{* *} \mathrm{P}<0.01 \mathrm{vs}$. negative control $(0 \mu \mathrm{M})$.

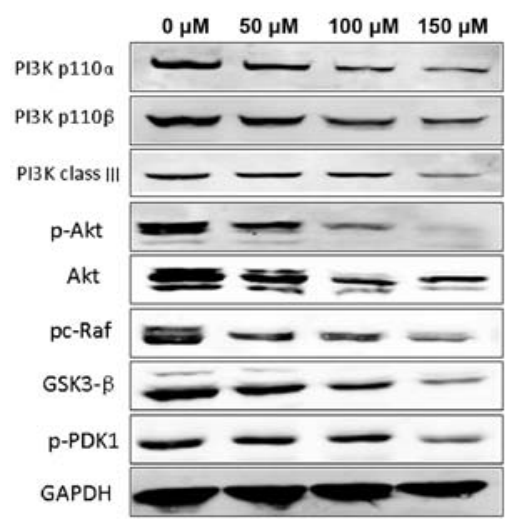

Figure 4. Western blot analysis of the expression of PI3K/Akt signaling pathway proteins and downstream proteins in Hep-2 cells after I3C treatment. Hep-2 cells were treated with $0,50,100$ and $150 \mu \mathrm{M}$ of I3C following which the expression of key proteins of the PI3K/Akt pathway and downstream proteins were analyzed by western blot assay. Expression of GAPDH served as an internal reference control.
100 or $150 \mu \mathrm{M} \mathrm{I3C}$, the apoptosis rate was $4.9 \pm 0.85,9.3 \pm 1.56$, $16.4 \pm 2.28$ and $42.5 \pm 5.32 \%$, respectively. For the untreated control the apoptosis rate was $4.3 \pm 0.76 \%$. Additionally, when comparing the $50,0 \mu \mathrm{M}$ and the untreated control groups, there was no statistically significant difference in the rate of apoptosis. Significant increases in the apoptosis rates were noted in the 100 and $150 \mu \mathrm{M}$ groups as compared with the $0 \mu \mathrm{M}$ and the untreated control groups $(\mathrm{P}<0.05, \mathrm{P}<0.01)$. This showed that a concentration of $100 \mu \mathrm{M}$ I3C induced apoptosis of Hep- 2 cells, and a concentration of $150 \mu \mathrm{M}$ significantly increased the proportion of apoptotic cells and displayed an apoptosis rate $>40 \%$ (Fig. 3). This suggested that the proportion of cells undergoing apoptosis following treatment with I3C was dose-dependent (Fig. 3).

Significantly reduced protein expression of PI3K/Akt in Hep-2 cells following treatment with $13 C$. We examined the expression of key signaling proteins of the PI3K/Akt pathway and 


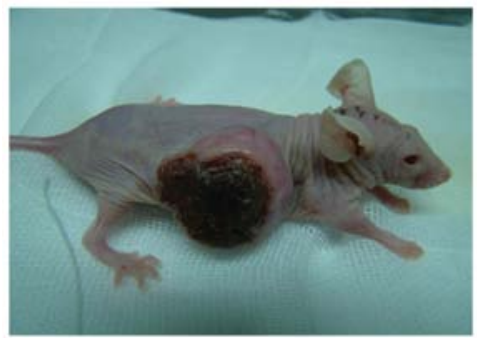

Negative control

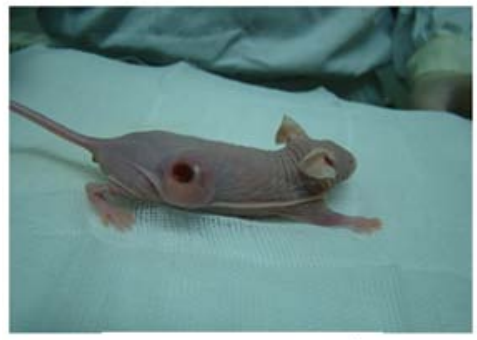

I3C pretreated

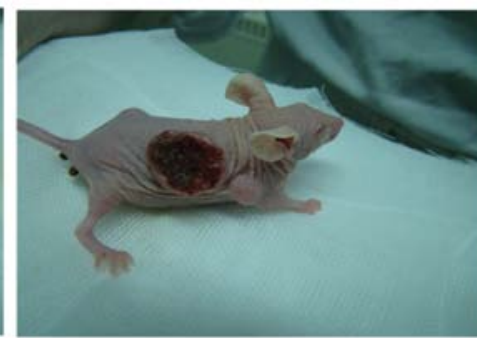

I3C treated

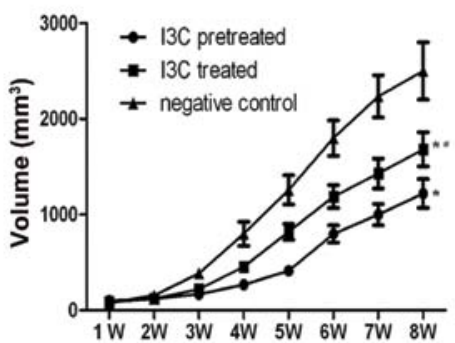

Figure 5. Tumor growth inhibition by I3C in tumor-transplanted animals. At the indicated time-points following Hep-2 cell transplantation, the average tumor volume $\left(\mathrm{mm}^{3}\right)$ was measured with a caliper. ${ }^{\mathrm{P}}<0.05$ vs. negative control. ${ }^{\#} \mathrm{P}<0.05$, I3C pretreated vs. I3C treated group (at week 8 ).

downstream signaling proteins associated with cancer cell proliferation and apoptosis. We found that in the untreated control and negative control groups, the protein expression of PI3K p110 $\alpha$, PI3K p110 $\beta$, PI3K class III, p-PDK1, Akt, p-Akt, p-c-Raf and GSK3- $\beta$ were all highly increased. Treatment of Hep- 2 cells with I3C markedly decreased the protein expression of PI3K p110 $\alpha$, PI3K p110 $\beta$, PI3K class III, p-PDK1, Akt, p-Akt, p-c-Raf and GSK3- $\beta$ when compared with these levels in the untreated groups, and the decreased expression levels of the signaling proteins was $\mathrm{I} 3 \mathrm{C}$ dose-dependent (Fig. 4).

Tumoricidal effects of $I 3 C$ in a $B A L B / c$ nude mouse model. We further investigated the tumoricidal effect of I3C in animal model experiments. The control mouse group received only conventional feed. These mice subsequently developed tumors of a large size; at week 8; the average volume of the tumors was $2456.5 \pm 266.3 \mathrm{~mm}^{3}$. By contrast, the mean volumes of the tumors in the $\mathrm{I} 3 \mathrm{C}$ treatment group and the pretreatment group were $1732.7 \pm 153.5 \mathrm{~mm}^{3}$ and $1263.6 \pm 134.4 \mathrm{~mm}^{3}$, respectively $(\mathrm{P}<0.05)$. This suggests that I3C significantly inhibited tumor growth $(\mathrm{P}<0.05)$, and that administration of $\mathrm{I} 3 \mathrm{C}$ prior to tumor transplantation was more effective than administration after transplantation of the tumor was established $(\mathrm{P}<0.05)$ (Fig. 5).

I3C treatment significantly reduces expression of PI3K/ $A K T$ and downstream signaling proteins in the transplanted tumors. We analyzed the expression of proteins related to the $\mathrm{PI} 3 \mathrm{~K} / \mathrm{AKT}$ pathway and downstream signaling pathways in the transplanted tumors and found that increasing concentrations of I3C were associated with reduced expression of PI3K p110 $\alpha$, PI3K p110 $\beta$, PI3K class III, p-PDK1, Akt, p-Akt, p-c-Raf and GSK3- $\beta$ signaling proteins. The lowest signaling protein expression was detected in the pretreatment group, followed

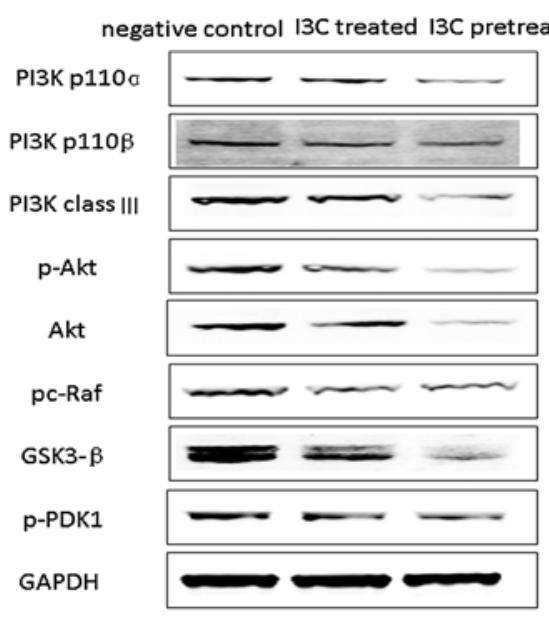

Figure 6. Hep-2 xenograft tumor model; I3C inhibition of tumor growth via the PI3K/Akt pathway. Eight weeks after tumor implantation, expression of proteins of the PI3K/Akt pathway in tumor tissue was analyzed by western blot analysis as described in Materials and methods. Expression of GAPDH served as an internal reference control. From left to right, the control group, the pretreatment group and the $\mathrm{I} 3 \mathrm{C}$ treatment group.

by the treatment group. As expected, the highest expression of the signaling proteins was found in the control group (Fig. 6).

No harmful side effects are noted in the heart, liver and kidney of I3C-treated nude mice. Specimens of the heart, liver and kidney obtained from the nude mice were sectioned and stained with H\&E. Pathological evaluation showed that treatment with I3C exerted no adverse effects on the heart, liver or kidney in the three groups of nude mice. No tissue damage such as structural degeneration or tissue necrosis was noted in any of the tissue specimens. These studies indicated that the 


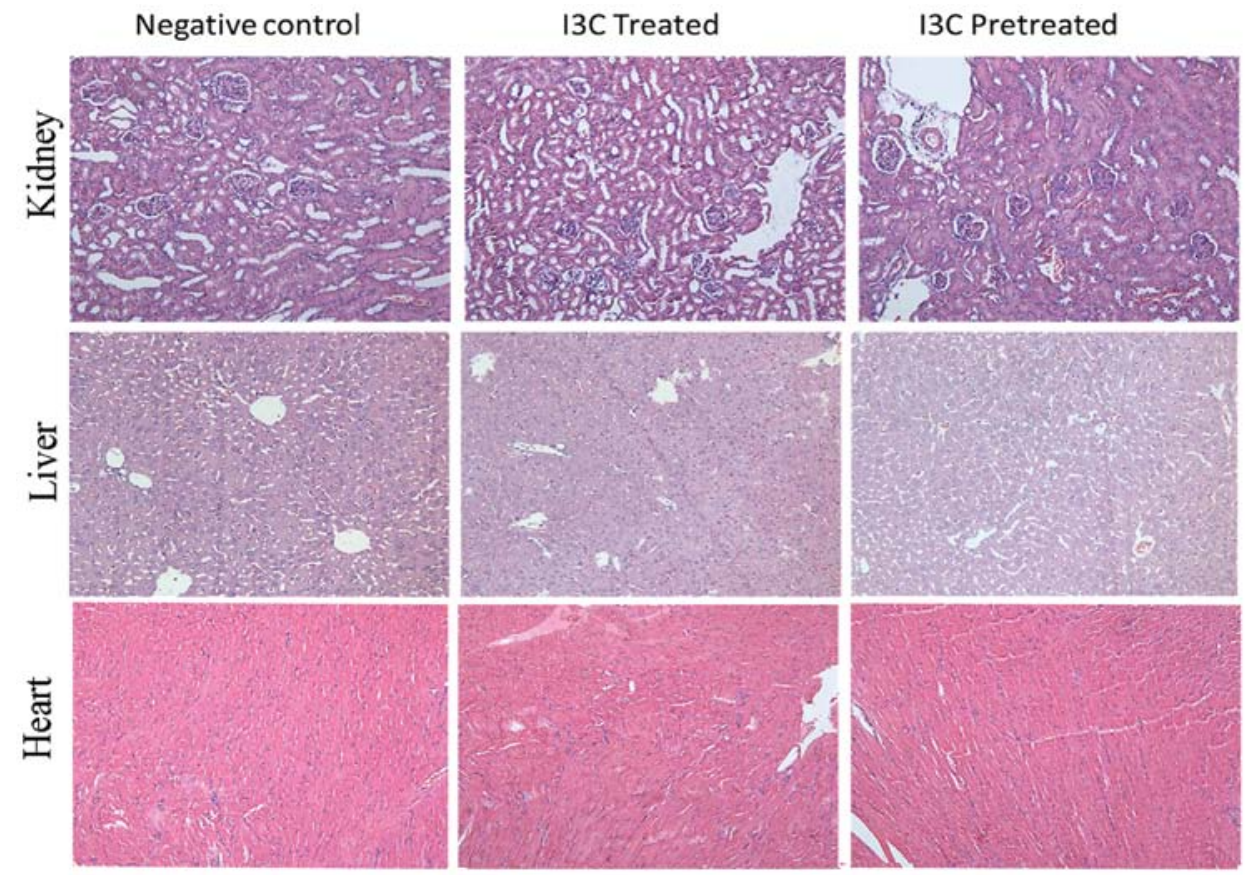

Figure 7. Hematoxylin and eosin (H\&E) staining of the heart, liver and kidney from I3C-treated nude mice. The heart, liver and kidney sections from the three groups of nude mice (from left to right: the control group, the treatment group and the pretreatment group) were stained with H\&E to observe and assess cell morphology and tissue structure (x100).

supplementation of the feed with $0.5 \%$ (w/w) I3C provoked no toxic side effects in any of the organs examined in the experimental mice (Fig. 7).

\section{Discussion}

Indole-3-carbinol is extracted from cruciferous vegetables by hydrolysis of glucosinolates (6). Many previous in vitro studies have shown that I3C causes significant growth inhibition of a variety of tumor cell lines by inducing cell cycle arrest and apoptosis $(8,10,12,17,18)$. However, the role of I3C in laryngeal cancer has remained largely unexplored. Our findings found that I3C significantly inhibited proliferation of Hep-2 cells and that $\mathrm{I} 3 \mathrm{C}$ at a dose of $150 \mu \mathrm{M}$ was an optimal concentration with the tumor inhibition rate of $65.97,87.45$ and $94.26 \%$ noted at 24 , 48 and $72 \mathrm{~h}$, respectively. The inhibitory mechanism involved alteration of the proliferation of cancer cells and induction of apoptosis. We observed that a dose of $100 \mu \mathrm{M}$ of I3C induced an apoptotic effect and that the apoptotic rate increased in an I3C dose-dependent manner. Rahman et al (10) reported that treatment of breast cancer cells with $30-100 \mu \mathrm{M}$ of I3C for 24-72 $\mathrm{h}$ induced apoptosis.

The PI3K/Akt pathway is associated with receptor tyrosine kinase signaling pathways. Mutational activation of pathway components can inappropriately activate PI3K and downstream target proteins Akt and phosphorylated Akt (p-Akt), and can subsequently result in phosphorylation and activation of mTORGSK3, mdm2, Bad, and members of the caspase family, that collectively play an important role in promoting tumor cell growth, proliferation, suppression of apoptosis, promotion of cellular invasion, tumor metastasis and angiogenesis (19). Abnormalities in the PI3K/Akt signaling pathway, in particular, and abnormal phosphorylation of Akt have been found to be closely associated with the development of tongue carcinoma and head and neck squamous cell carcinomas $(15,20)$.

To further clarify the potential relationship between I3C-induced apoptosis and the PI3K/Akt signaling pathway in laryngeal cancer, we analyzed the differential expression of PI3K/Akt pathway-specific signaling proteins and their cognate downstream proteins both before and after treatment with I3C. Markedly decreased expression of PI3K p110 $\alpha$, PI3K p110 $\beta$, PI3K class III, p-PDK1, Akt, p-Akt, p-c-Raf and GSK3- $\beta$ in Hep- 2 cells was noted following treatment with I3C as compared with levels in the untreated cells. This observation suggests that inhibition of laryngeal cancer cell proliferation and induction of apoptosis is closely associated with the PI3K/ Akt signaling pathway and the findings are concordant with those found in breast or prostate cancer $(8,21)$.

Previous animal studies $(16,17)$ demonstrated that I3C inhibits the occurrence and development of solid tumors. Previous studies of cervical cancer revealed that the antitumor mechanism of I3C was partly dependent on the increase in the permeability of the tumor cell membrane, activation of caspase-3 and thus induction of cancer cell apoptosis (22). When mice with prostate cancer (TRAMP) were fed diets containing $1 \%(\mathrm{w} / \mathrm{w}) \mathrm{I} 3 \mathrm{C}$ over a period of 10 weeks, tumor cell apoptosis was induced (23) and Nrf2 was activated, which is a pathway known to regulate antioxidant signaling pathways. Newfield et al (24) reported that the immune response of mice fed with $\mathrm{I} 3 \mathrm{C}$ could be triggered to produce the anti-proliferative agent 2-hydroxy estrone. Our animal experiments confirmed that $\mathrm{I} 3 \mathrm{C}$ effectively inhibited the growth of laryngeal cancer and that $\mathrm{I} 3 \mathrm{C}$ intervention significantly decreased laryngeal tumor growth in nude mice when compared with the control mice. It is worth noting here that the graft tumor growth rate was slower in the pretreatment group than that noted in the 
treated mouse group, suggesting that $\mathrm{I} 3 \mathrm{C}$ effectively prevents the occurrence and development of solid tumors. This observation also suggests that $\mathrm{I} 3 \mathrm{C}$ can be considered as an alternative therapeutic approach for the prevention and treatment of laryngeal cancer.

Consistent with the results obtained from the in vitro experiments in the pretreated and treated nude mice, we found that the expression levels of PI3K p110 $\alpha$, PI3K p110 $\beta$, PI3K class III, p-PDK1, Akt, p-Akt, p-c-Raf and GSK3- $\beta$ were significantly downregulated when compared with the levels in the control group not treated with I3C. This observation indicates that abnormal activation of the PI3K/Akt pathway may play a key role in the process of laryngeal squamous cell carcinoma. Our animal experiments also confirmed that I3C downregulated protein expression in the PI3K/Akt signaling pathway in the transplanted tumors.

Using I3C to treat MCF10CA1a breast cancer cells and homologous CF10A mammary epithelial cells, Rahman et al (10) found that I3C only induced MCF10CA1a breast cancer cell apoptosis (10), suggested that I3C was without risk to nontumor cells. Consistently, our experiment also confirmed that $\mathrm{I} 3 \mathrm{C}$ caused growth inhibition only in the transplanted tumors in nude mice, and did not provoke any degenerative harm to the heart, liver, kidney and other organs with low cytotoxicity to normal cells.

In summary, our in vivo and in vitro experiments demonstrated that I3C significantly inhibits laryngeal cancer cell proliferation and induces apoptosis. We suggest that the observed effects of I3C are likely associated with the regulation of the PI3K/Akt signaling pathway and dowstream protein expression. Due to the effective, non-toxic, natural antitumor properties, I3C is considered to be a likely preventive and curative candidate for laryngeal cancer. Additional studies are required to determine the underlying mechanisms whereby I3C suppresses laryngeal cancer at the molecular level, and to provide a theoretical basis for the tumoricidal and clinical utility of I3C.

\section{Acknowledgements}

This study was supported by grants from the National Natural Science Foundation of China (no. 30901662), and the Science and Technology Program of Wuhan City (nos. 200951199455 and 200950431168).

\section{References}

1. Jemal A, Bray F, Center MM, Ferlay J, Ward E and Forman D: Global cancer statistics. CA Cancer J Clin 61: 69-90, 2011.

2. Michaud DS, Spiegelman D, Clinton SK, Rimm EB, Willett WC and Giovannucci EL: Fruit and vegetable intake and incidence of bladder cancer in a male prospective cohort. J Natl Cancer Inst 91: 605-613, 1999.

3. Annema N, Heyworth JS, McNaughton SA, Iacopetta B and Fritschi L: Fruit and vegetable consumption and the risk of proximal colon, distal colon, and rectal cancers in a case-control study in Western Australia. J Am Diet Assoc 111: 1479-1490, 2011 .

4. Larsson SC, Hakansson N, Näslund I, Bergkvist L and Wolk A: Fruit and vegetable consumption in relation to pancreatic cancer risk: a prospective study. Cancer Epidemiol Biomarkers Prev 15: 301-305, 2006
5. van Poppel G, Verhoeven DT, Verhagen H and Goldbohm RA Brassica vegetables and cancer prevention. Epidemiology and mechanisms. Adv Exp Med Biol 472: 159-168, 1999.

6. Keck AS and Finley JW: Cruciferous vegetables: cancer protective mechanisms of glucosinolate hydrolysis products and selenium. Integr Cancer Ther 3: 5-12, 2004.

7. Shertzer H and Senft A: The micronutrient indole-3-carbinol: implications for disease and chemoprevention. Drug Metabol Drug Interact 14: 159-188, 2011.

8. Chinni SR, Li Y, Upadhyay S, Koppolu PK and Sarkar FH: Indole-3-carbinol (I3C) induced cell growth inhibition, G1 cell cycle arrest and apoptosis in prostate cancer cells. Oncogene 20: 2927-2936, 2001.

9. Brew CT, Aronchik I, Hsu JC, et al: Indole-3-carbinol activates the ATM signaling pathway independent of DNA damage to stabilize p53 and induce G1 arrest of human mammary epithelial cells. Int J Cancer 118: 857-868, 2006.

10. Rahman KM, Aranha O and Sarkar FH: Indole-3-carbinol (I3C) induces apoptosis in tumorigenic but not in nontumorigenic breast epithelial cells. Nutr Cancer 45: 101-112, 2003.

11. Meng Q, Qi M, Chen DZ, et al: Suppression of breast cancer invasion and migration by indole-3-carbinol: associated with up-regulation of BRCA1 and E-cadherin/catenin complexes. J Mol Med 78: 155-165, 2000.

12. Aggarwal BB and Ichikawa $\mathrm{H}$ : Molecular targets and anticancer potential of indole-3-carbinol and its derivatives. Cell Cycle 4: 1201-1215, 2005

13. Chang F, Lee JT, Navolanic PM, et al: Involvement of PI3K/Akt pathway in cell cycle progression, apoptosis, and neoplastic transformation: a target for cancer chemotherapy. Leukemia 17: 590-603, 2003

14. Fresno Vara JA, Casado E, de Castro J, Cejas P, Belda-Iniesta C and González-Barón M: PI3K/Akt signalling pathway and cancer. Cancer Treat Rev 30: 193-204, 2004.

15. Watanabe S, Sato K, Okazaki Y, Tonogi M, Tanaka Y and Yamane GY: Activation of PI3K-AKT pathway in oral epithelial dysplasia and early cancer of tongue. Bull Tokyo Dent Coll 50: $125-133,2009$.

16. Oganesian A, Hendricks JD and Williams DE: Long term dietary indole-3-carbinol inhibits diethylnitrosamine-initiated hepatocarcinogenesis in the infant mouse model. Cancer Lett 118: 87-94, 1997.

17. Plate AY and Gallaher DD: Effects of indole-3-carbinol and phenethyl isothiocyanate on colon carcinogenesis induced by azoxymethane in rats. Carcinogenesis 27: 287-292, 2006.

18. Pappa G, Lichtenberg M, Iori R, Barillari J, Bartsch H and Gerhäuser C: Comparison of growth inhibition profiles and mechanisms of apoptosis induction in human colon cancer cell lines by isothiocyanates and indoles from Brassicaceae. Mutat Res 599: 76-87, 2006.

19. Brognard J, Clark AS, Ni Y and Dennis PA: Akt/protein kinase B is constitutively active in non-small cell lung cancer cells and promotes cellular survival and resistance to chemotherapy and radiation. Cancer Res 61: 3986-3997, 2001.

20. Cicenas J: The potential role of Akt phosphorylation in human cancers. Int J Biol Markers 23: 1-9, 2008.

21. Rahman KM, Li Y and Sarkar FH: Inactivation of akt and NF- $\kappa B$ play important roles during indole-3-carbinol-induced apoptosis in breast cancer cells. Nutr Cancer 48: 84-94, 2004.

22. Chen DZ, Qi M, Auborn KJ and Carter TH: Indole-3-carbinol and diindolylmethane induce apoptosis of human cervical cancer cells and in murine HPV16-transgenic preneoplastic cervical epithelium. J Nutr 131: 3294-3302, 2001.

23. Wu TY, Saw CL, Khor TO, Pung D, Boyanapalli SS and Kong AN: In vivo pharmacodynamics of indole-3-carbinol in the inhibition of prostate cancer in transgenic adenocarcinoma of mouse prostate (TRAMP) mice: involvement of Nrf2 and cell cycle/apoptosis signaling pathways. Mol Carcinog 51: 761-770, 2012.

24. Newfield L, Goldsmith A, Bradlow HL and Auborn K: Estrogen metabolism and human papillomavirus-induced tumors of the larynx: chemo-prophylaxis with indole-3-carbinol. Anticancer Res 13: 337-341, 1993. 